\title{
Identification of a dysfunctional microglial population in human Alzheimer's disease cortex using novel single-cell histology image analysis
}

\author{
Molly E. V. Swanson 1,2,6 (D, Emma L. Scotter ${ }^{2,3}$, Leon C. D. Smyth²,4, Helen C. Murray ${ }^{1,2}$, Brigid Ryan 1,2, \\ Clinton Turner ${ }^{5}$, Richard L. M. Faull ${ }^{1,2}$, Mike Dragunow ${ }^{2,4}$ and Maurice A. Curtis ${ }^{1,2^{*}}$
}

\begin{abstract}
In Alzheimer's disease (AD), microglia are affected by disease processes, but may also drive pathogenesis. AD pathology-associated microglial populations have been identified with single-cell RNA-Seq, but have not been validated in human brain tissue with anatomical context. Here, we quantified myeloid cell markers to identify changes in AD pathology-associated microglial populations. We performed fluorescent immunohistochemistry on normal $(n=8)$ and $\mathrm{AD}(\mathrm{n}=8)$ middle temporal gyri, co-labelling the pan-myeloid cell marker, Iba1, with one of 11 markers of interest (MOIs): CD45, HLA-DR, CD14, CD74, CD33, CD206, CD32, CD163, P2RY12, TMEM119, L-Ferritin. Novel image analyses quantified the single-cell abundance of Ibal and each MOI. Each cell was gated into one Iba1-MOI population (Iba 1 low $\mathrm{MOl}^{\text {high }}$, Iba ${ }^{\text {high }} \mathrm{MOI}^{\text {high }}$, or Iba $1^{\text {high }} \mathrm{MOI}^{\text {low }}$ ) and the abundance of each population was compared between AD and control. Triple-labelling of L-Ferritin and Iba1 with a subset of MOls was performed to investigate L-Ferritin-MOI coexpression on Iba1 ${ }^{\text {low }}$ cells. Iba $1^{\text {low }} \mathrm{MOI}^{\text {high }}$ myeloid cell populations delineated by MOls CD45, HLA-DR, CD14, CD74, $\mathrm{CD} 33, \mathrm{CD} 32$, and L-Ferritin were increased in AD. Further investigation of the Iba $1^{\text {low }} \mathrm{MO} \mathrm{I}^{\text {high }}$ populations revealed that their abundances correlated with tau, but not amyloid beta, load in AD. The Iba $1^{\text {low }}$ microglial population highly expressed L-Ferritin, reflecting microglial dysfunction. The L-Ferritin ${ }^{\text {high }} \mathrm{CD} 74^{\text {high }} \mathrm{HLA}$-DR ${ }^{\text {high }}$ phenotype of the Iba $1^{\text {low }}$ population mirrors that of a human AD pathology-associated microglial subpopulation previously identified using single-cell RNA-Seq. Our high-throughput immunohistochemical data with anatomical context support the microglial dysfunction hypothesis of AD.
\end{abstract}

Keywords: Microglia, Alzheimer's disease, Tau, Amyloid beta, Dysfunction, Immunohistochemistry, Single-cell analysis

\section{Background}

Alzheimer's disease (AD) pathology is characterised by the accumulation of amyloid beta plaques and hyperphosphorylated tau tangles [1]. The aggregation of amyloid beta proteins precipitates inflammatory reactions by microglia, the innate immune cells of the central nervous

\footnotetext{
*Correspondence: m.curtis@auckland.ac.nz

1 Department of Anatomy and Medical Imaging, Faculty of Medical and Health Science, University of Auckland, Private Bag 92019, Auckland, New Zealand

Full list of author information is available at the end of the article
}

system [2, 3]. Genetic risk factors for AD include loss-offunction mutations in microglia-specific genes, including CD33 and TREM2, which are associated with reduced microglial phagocytic capacity [4-7]. Such microglialspecific genetic risk factors for AD suggest that microglial reactions are not only a result of disease processes, but may drive disease pathogenesis.

Changes in microglial function may impact the development of $\mathrm{AD}$ through different processes. The proinflammatory microglia hypothesis that posits that deposition of amyloid beta and subsequent phagocytosis by microglia drive chronic microglial activation, making original author(s) and the source, provide a link to the Creative Commons licence, and indicate if changes were made. The images or other third party material in this article are included in the article's Creative Commons licence, unless indicated otherwise in a credit line to the material. If material is not included in the article's Creative Commons licence and your intended use is not permitted by statutory regulation or exceeds the permitted use, you will need to obtain permission directly from the copyright holder. To view a copy of this licence, visit http://creativecommons.org/licenses/by/4.0/. The Creative Commons Public Domain Dedication waiver (http://creativeco mmons.org/publicdomain/zero/1.0/) applies to the data made available in this article, unless otherwise stated in a credit line to the data. 
them 'neurotoxic' $[8,9]$. Alternatively, the microglial dysfunction hypothesis proposes that $\mathrm{AD}$ pathogenesis is modified by loss of normal microglial function, encompassing both dysregulated microglial activation and loss of microglial 'neurosupportive' function [10-14]. With two disparate hypotheses, it is unclear whether microglial activity should be enhanced or reduced in order to reduce $A D$ pathology, although it is also possible that both hypotheses are correct but reflect different stages of progression.

Indeed, the traditional dogma of microglia existing in either a pro-inflammatory 'neurotoxic' or anti-inflammatory 'neurosupportive' state in the human brain oversimplifies the heterogeneity of microglial reactions [15]. Microglial heterogeneity in the normal and diseased brain is now being characterised using novel technologies, including single-cell and single-nuclei RNA sequencing [16-19]. AD pathology-associated microglial subpopulations with unique transcriptomic signatures have been identified, including a population with enriched expression of FTL (L-Ferritin), HLA-DRA, $H L A-D R B 1, C D 14$, and CD74 [16, 17] (Additional file 1: Table S1). However, these studies require the dissociation of cells from whole tissue. As such, they are unable to resolve whether changes in microglial populations are driven by human $\mathrm{AD}$ pathology or quantify the anatomical location of microglia with unique expression profiles relative to amyloid beta and tau in the brain.

By contrast, immunohistochemical studies in the postmortem human brain have identified significant changes in the expression of single proteins in microglia associated with amyloid and tau pathology, including HLA-DR, CD45, CD14, CD32, CD163, and L-Ferritin, which are proposed to alter microglial function and influence disease pathogenesis $[6,16,17,20-51]$ (Additional file 1: Table S1). Despite growing evidence linking microglial changes to $\mathrm{AD}$ pathogenesis, a recent systematic review revealed marked differences in microglial protein changes in post-mortem human AD tissue between studies (for review see Hopperton et al. [48]). The most consistent changes identified include increases in classical 'activation' proteins, like HLA-DR and CD68, while numerous other proteins with more specific functions show high variability between studies or are infrequently assessed [48].

A key contributor to this variability between immunohistochemical studies is the methodology employed to quantify microglial protein abundance. In this study, we developed a novel single-cell image analysis pipeline to investigate multiple myeloid cell markers previously identified as altered in the human $\mathrm{AD}$ brain or enriched in an AD pathology-associated microglial population. The markers included proteins more highly expressed by, or specifically expressed by, perivascular macrophages. Because all myeloid cell markers selected for investigation in this study have significance to $\mathrm{AD}$, we have collectively termed them markers of interest (MOI). The advantages of our approach are identification of multiple key microglial proteins, quantification of their abundance at the single cell level, and retaining anatomical context allowing correlation of marker abundance in proximity to amyloid and tau.

Specifically, we investigated the single cell abundance of eleven MOIs (Additional file 1: Table S1) across microglial and perivascular macrophage populations in immunohistochemically stained normal and AD cortex; CD45, HLA-DR, CD14, CD74, CD33, CD206, CD32, CD163, P2RY12, TMEM119, and L-Ferritin. Changes in protein expression were quantified at the single cell level and reflect not only any overall microglial changes in $\mathrm{AD}$, but changes in specific populations associated with the AD pathology markers, amyloid beta, and tau. This work demonstrates a clearer picture of multiple microglial population changes in AD human brain.

\section{Methods}

\section{Human tissue selection}

Formalin-fixed middle temporal gyrus (MTG) blocks from eight neurologically normal and eight $A D$ cases from the Neurological Foundation Human Brain Bank were used in this study (Table 1). The AD cases had a history of dementia and were considered at least intermediate AD, based on their National Institute of AgingAlzheimer's Association (NIA-AA) 'ABC' score. Cases with Lewy body disease or other neurodegenerative pathology were excluded. Normal cases had no previous history of neurological disorders and cause of death was unrelated to any neurological condition. An initial independent pathology assessment reported no other disease pathology aside from normal age-related amyloid presence. The eight normal cases were included in the analysis based on this first pathology assessment. A more comprehensive pathology assessment, including determination of the ' $A B C$ ' scores, was carried out on all normal cases following our analysis. Of the eight normal cases, seven showed no or low AD neuropathologic changes. However, one normal case (H187) showed an intermediate $\mathrm{AD}$ neuropathologic change despite the initial pathology report suggesting pathological changes were in the normal range for its age. Given the changes were not high AD changes, the relatively older age of this case, and the lack of neurological 
Table 1 Human cases used for this study

\begin{tabular}{lllll}
\hline Case & Age (years) & Sex & $\begin{array}{l}\text { Post- } \\
\text { mortem } \\
\text { delay (h) }\end{array}$ & $\begin{array}{l}\text { NIA-AA staging (AD } \\
\text { neuropathologic } \\
\text { change) }\end{array}$ \\
\hline Normal & & & & \\
H169 & 81 & Male & 24 & A2 B0 C1 (none) \\
H180 & 73 & Male & 33 & A2 B0 C1 (none) \\
H187 & 98 & Female & 15 & A2 B2 C1 (intermediate) \\
H191 & 77 & Male & 25 & A0 B0 C0 (none) \\
H196 & 85 & Male & 15 & A1 B0 C0 (none) \\
H229 & 88 & Female & 17 & A2 B1 C2 (low) \\
H243 & 77 & Female & 13 & A0 B0 C0 (none) \\
H246 & 89 & Male & 17 & A0 B1 C0 (none) \\
Mean & $83.5 \pm 9.1$ & - & $19.3 \pm 6.5$ & - \\
AD & & & & A3 B3 C2 (high) \\
AZ99 & 94 & Female & 8.5 & A3 B2 C2 (intermediate) \\
AZ102 & 84 & Female & 14.5 & A2 B3 C1 (intermediate) \\
AZ107 & 86 & Male & N/A & A3 B3 C2 (high) \\
AZ108 & 94 & Female & 11.5 & A3 B2 C1 (intermediate) \\
AZ109 & 90 & Female & 31 & A3 B3 C2 (high) \\
AZ110 & 86 & Female & 15 & A3 B3 C2 (high) \\
AZ113 & 77 & Male & 3.5 & A3 B2 C2 (intermediate) \\
AZ119 & 89 & Male & 5 & - \\
Mean & $87.5 \pm 5.6$ & - & $12.7 \pm 9.2$ & \\
\hline
\end{tabular}

symptoms at time of death, we have maintained the normal classification of this case for our analysis.

\section{Free-floating immunohistochemistry}

All MOIs investigated in this study were co-labelled with the pan-myeloid cell marker, Iba1, ensuring that functional changes across microglial and perivascular macrophage populations were assessed. As part of the Neurological Foundation Human Brain Bank procedures, the MTG is cut into 4 blocks, of which we used one for this study; typically block 1 or 2 to ensure we were sampling from the middle of the MTG in all cases [52]. For Iba1 co-labelling with MOIs, three 50- $\mu \mathrm{m}$ thick MTG sections approximately $800 \mu \mathrm{m}$ apart were selected. Freefloating fluorescent immunohistochemistry was performed as previously described $[53,54,57]$. Sections were incubated in Tris-EDTA pH 9.0 for antigen retrieval, and subsequently in primary antibodies against Iba1 and an immunophenotype MOI (Additional file 1: Table S2). Iba1 was visualised using AlexaFluor ${ }^{\circledR} 594$ - or 647-conjugated secondary antibody and immunophenotype MOIs were visualised using AlexaFluor ${ }^{\circledR} 488$ - or 594-conjugated secondary antibody or the AlexaFluor ${ }^{\circledR} 488$ TSA protocol (Additional file 1: Table S2). For AD pathology load analysis, two MTG sections approximately $800 \mu \mathrm{m}$ apart were selected per pathology stain. Formic acid antigen retrieval was performed to unmask aggregate epitopes. Sections were incubated in anti-amyloid beta and anti-tau antibodies, visualised using speciesspecific AlexaFluor ${ }^{\circledR}$-conjugated secondary antibodies. Nuclei were counterstained with Hoechst. Sections were mounted using PBS and coverslipped using ProLong ${ }^{\circledR}$ Diamond Antifade mounting media.

For representative images demonstrating each MOI colabelling with Iba1, sections were imaged on an Olympus FV1000 confocal microscope $(60 \times$ oil). Optical $z$-stacks were taken through the entirety of the cell body and processes. For quantification, MTG grey matter images were acquired for each section using a Nikon Ni-E microscope $(20 \times, 0.5 \mathrm{NA})$ with Nikon DS-Ri2 and Qi2 cameras and a motorised stage. Regions of interest (ROIs) encompassing grey matter layers I-VI were imaged based on the Hoechst counterstain. These images were used for (1) the tissue-wide integrated intensity analysis, (2) the singlecell Iba1-MOI analysis for both Iba1-MOI and Iba1-LFerritin-MOI co-labelling, and (3) the AD pathology load analysis.

\section{Paraffin immunohistochemistry}

For the amyloid beta spatial analysis, two sequential $10-\mu \mathrm{m}$ thick MTG sections were selected from AD cases and received two immunohistochemical staining rounds; Iba1/L-Ferritin/HLA-DR, then amyloid beta/tau. Paraffin immunohistochemistry was performed as previously described [58]. Tris-EDTA pH 9.0 antigen retrieval was performed, and sections incubated in primary then AlexaFluor ${ }^{\circledR}$-conjugated secondary antibody mixtures. Nuclei were counterstained with Hoechst. Sections were mounted using PBS and coverslipped using ProLong ${ }^{\circledR}$ Diamond Antifade mounting media. After this first round of immunohistochemistry, sections were imaged on a Zeiss Z2 Axioimager $(20 \times)$ using MetaSystems VSlide acquisition software and MetaCyte stitching software. Sections were then de-coverslipped for AD pathology staining as described above. Sections were imaged after this second round of immunohistochemical staining using the same imaging system.

Images from both staining rounds were opened on VSViewer v2.1.112 and individual channel images extracted from three areas of grey matter per section. Hoechst-stained nuclei in each labelling round were used as intrinsic markers for image registration. Hoechst images were first pre-processed (smoothed) in ImageJ (v1.52p) by applying a 50-pixel rolling background subtraction and a 5-pixel median filter. The processed nuclear images were then registered to each other using a custom-designed Python code. Jupyter Notebook was used to implement an AKAZE affine registration, and a transformation matrix was extracted and applied to all 
the individual images in the set [55]. These six channel images were used for the amyloid beta spatial analysis.

\section{Quantification using MetaMorph custom image analysis pipelines}

Four novel custom image analysis journals were developed in MetaMorph software (Molecular Devices) to quantify Iba1-MOI populations with respect to $\mathrm{AD}$ pathology in normal and AD MTG. Journals for tissuewide integrated intensity analysis, single-cell Iba1-MOI analysis, and amyloid beta spatial analysis are detailed in Additional file 1: Figure S1. All image analysis journals, and validation of their accuracy, are described in detail in the supplementary materials.

The tissue-wide integrated intensity analysis measured the integrated intensity of each MOI within all Iba1-MOI cells in the MTG. Binary masks of both the Iba1 staining and the MOI staining were generated using an adaptive threshold tool and combined to create a "master mask" containing all Iba1-MOI cells. MOI integrated intensity within the master mask was measured. MOI integrated intensity data were normalised to the region of interest tissue area and are thus equivalent to the concentration of the MOI in the tissue.

The single cell Iba1-MOI analysis measured the single-cell average intensity of Iba1 and the MOI from each Iba1-MOI co-label. The Iba1-MOI "master mask" described above was used. Each object within the master mask was considered a 'cell', and the average intensity of Iba1 and the MOI measured in each cell. Average intensity per Iba1-MOI cell is equivalent to the protein concentration per cell. Iba1 and MOI average intensities were plotted on an $X Y$ scatter plot. All Iba1-MOI cells from all $\mathrm{AD}$ and normal cases were pooled and Iba1MOI populations segregated using a freehand tool, generating gates. Three Iba1-MOI populations were gated; Ibal ${ }^{\text {low }} \mathrm{MOI}^{\text {high }}$, Iba $1^{\text {high }} \mathrm{MOI}^{\text {high }}$, and Iba $1^{\text {high }} \mathrm{MOI}^{\text {low }}$. The three population gates were transferred from the pooled Iba1-MOI plot to the $x y$ scatter plot for each normal and AD case. The abundance of cells in each Iba1MOI population (as a proportion of total Iba1-MOI cells per case) and the mean population intensity of each MOI were measured. Changes in the proportions of cells within each of the three Iba1-MOI populations reflected changes in Iba1 and MOI expression relative to one another. There was no difference in the overall number of Iba1-MOI cells between normal and AD cases (Additional file 1: Table S3). The mean intensity of each MOI population, equivalent to mean fluorescence intensities for flow cytometry data, was used to identify changes in MOI expression parallel to changes in Iba1 expression.
The AD pathology load analysis measured the load of amyloid beta and tau in the MTG. Binary masks of amyloid beta and tau staining were generated using the adaptive threshold tool, and the area of each mask was measured. Data are presented as the mean percentage area of amyloid beta or tau staining across the region of interest against the abundance of each $\mathrm{Iba}^{\text {low }} \mathrm{MOI}^{\text {high }}$ population.

The amyloid beta spatial analysis was a modified version of the single-cell Iba1-MOI analysis. Iba1 and MOI average intensity, and distance between each Iba1-MOI cell and its nearest amyloid beta plaque, was measured. Within each cell in the master mask, the intensity of a binary mask of amyloid beta binary was measured. If the intensity of the amyloid beta mask within a cell was above 0 , the cell was on or interacting with an amyloid beta plaque and assigned as 'plaque. The amyloid beta master mask was subsequently dilated circularly in $5 \mu \mathrm{m}$ increments. After each dilation, the intensity of the dilated amyloid beta mask was measured within each cell in the master mask. The dilations were discontinued at $50 \mu \mathrm{m}$. The distances were grouped as "plaque", "plaqueadjacent" (up to $50 \mu \mathrm{m}$ from a plaque) or "non-plaque" (greater than $50 \mu \mathrm{m}$ from a plaque).

\section{Statistical analysis}

F test of equality of variances and the Shapiro-Wilk normality were used to determine whether the variances between the two groups being compared were equal and if the data were normally distributed, respectively. If the variances were equal and the data were normally distributed, parametric tests were used. The student's t test was used to compare between two groups, while the Pearson correlation was used for correlations of measured values with disease pathology, age, and post-mortem delay. The effect of sex was tested by one-way ANOVA with HolmSidak's multiple comparisons. For non-parametric data, the Mann-Whitney test was used to compare between two groups, while the Spearman correlation was used for correlations of measured values with disease pathology, age, and post-mortem delay. The effect of sex was tested by the Kruskal-Wallis test with Dunn's multiple comparisons. There were no significant correlations of any measured values with age, post-mortem delay, or sex in the normal or AD groups. Thus, these data were not discussed further. All data are presented as mean \pm standard deviation, with statistical significance set at $p \leq 0.05$. Correlations were considered strong if $r \geq 0.8$ and moderate if $0.8 \geq r \geq 0.7$. 


\section{Results}

An lba $1^{\text {low }}$ myeloid cell population is more abundant in the AD temporal cortex

We co-labelled Iba1 with one of 11 myeloid cell markers using immunohistochemistry on normal and $\mathrm{AD}$
MTG: CD45, HLA-DR, CD14, CD74, CD33, CD206, CD32, CD163, P2RY12, TMEM119, or L-Ferritin. All 11 myeloid cell markers were specifically expressed by Iba1positive cells in both the normal and AD MTG (Fig. 1). Before performing more comprehensive analyses, we
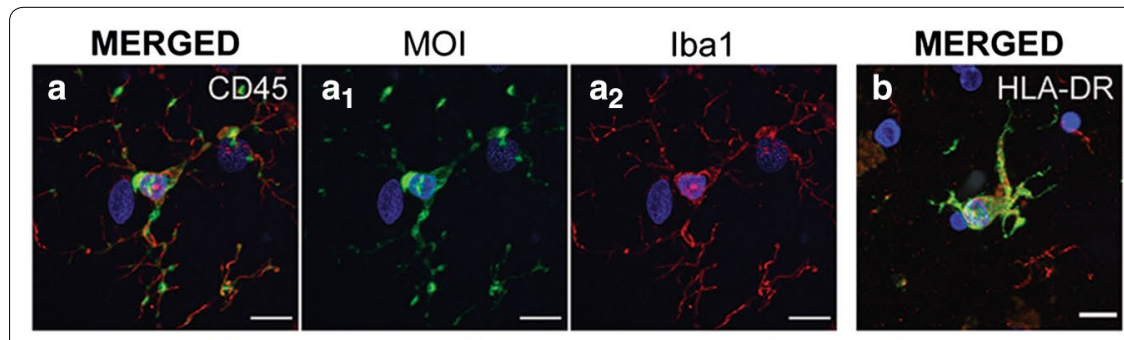

Iba1
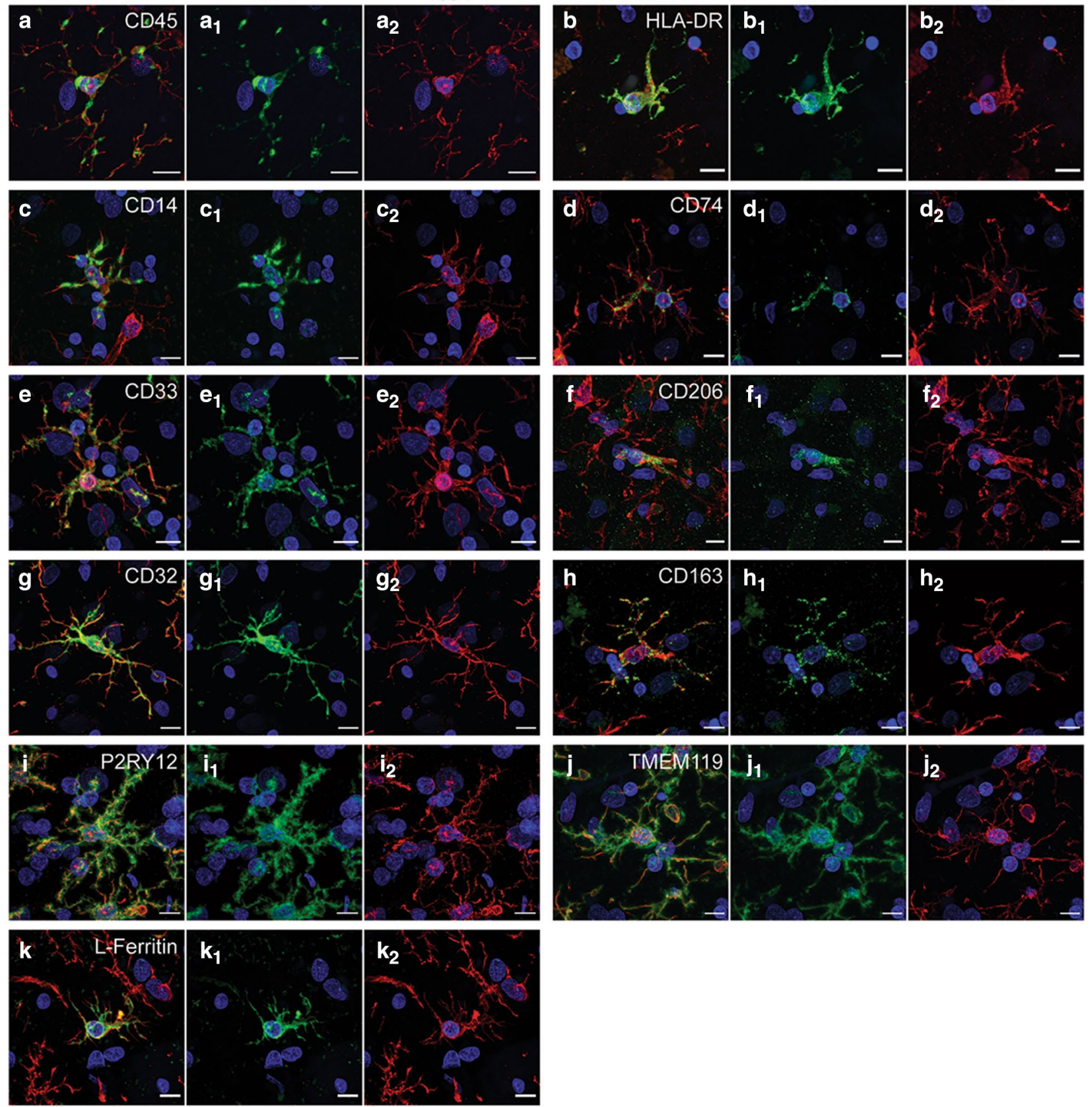

Fig. 1 Co-labelling of MOls with Iba1 in the human middle temporal gyrus. Pan myeloid cell marker, Iba1, was immunofluorescently co-labelled with one of the 11 MOls investigated in the normal and AD human middle temporal gyrus; CD45 (a), HLA-DR (b), CD14 (c), CD74 (d), CD33 (e), CD206 (f), CD32 (G), CD163 (h), P2RY12 (I), TMEM119 (j), and L-Ferritin (k). Representative images are maximum projections of confocal z-stacks to demonstrate co-labelling of each MOI (green) co-labelling and Ibal (red) with a Hoechst counterstain (blue); scale bars =10 $\mu \mathrm{m}$ 
measured the total integrated intensity across the sections to determine changes in tissue-wide expression in AD (Additional file 1: Figure S2). Of the 11 MOIs, only the expression of $\mathrm{CD} 45$ was significantly increased in $\mathrm{AD}$ (Additional file 1: Figure S2).

Given that microglial sub-populations with unique transciptomic signatures have been identified in human AD brain tissue with single-cell RNA sequencing technologies [16-19], we sought to investigate microglial protein expression changes in immunohistochemically stained tissue at a single-cell level. We developed a custom MetaMorph image analysis pipeline which allowed for single-cell measurements of Iba1 and MOI staining intensity in post-mortem human tissue (Fig. 2A). The individual cell expression data was treated like FACS data (Fig. 2): for each Iba1-MOI co-label, we plotted all Iba1MOI cells on an $X Y$ scatter plot based on their Iba1 and MOI average intensities and manually gated Iba1-MOI populations. For 10 of the 11 MOIs (CD45, HLA-DR, CD14, CD74, CD33, CD206, CD32, CD163, P2RY12, and TMEM119), three Iba1-MOI populations were identified: 1 . Iba $1^{\text {low }} \mathrm{MOI}^{\text {high }}$, 2. Iba ${ }^{\text {high }} \mathrm{MOI}^{\text {high }}$, and 3. Iba $1^{\text {high }}$ $\mathrm{MOI}^{\text {low }}$ (Fig. 2B, D, F, H, J, L, M, O, Q, and S). In contrast, for L-Ferritin only two Iba1-L-Ferritin populations were identified (labelled as 1 and 3): 1 . Iba $1^{\text {low }}$ L-Ferritin ${ }^{\text {high }}$ and 3. Iba $1^{\text {high }}$ L-Ferritin ${ }^{\text {low }}$ (Fig. 2U). This finding indicates that the Ibal ${ }^{\text {low }}$ population was best delineated by high L-ferritin expression: if a cell expressed Iba1 at a low level it always expressed L-ferritin at a high level, and vice versa. Therefore, the Iba $1^{\text {low }}$ population was not uniquely identified by high expression of one or a subset of the myeloid cell markers investigated.

For all myeloid cell markers, the intensity distributions of cells positive for Iba1 and/or the MOIs changed in $\mathrm{AD}$, as reflected in the net difference plot for each marker (Fig. 2, Additional file 1: Table S4). When quantified, the most notable change in the abundances of the Iba1-MOI populations identified was a significant increase in the proportion of the Ibal ${ }^{\text {low }} \mathrm{MOI}^{\text {high }}$ population for seven of the 11 MOIs in AD (Fig. 3): CD45, HLA-DR, CD14, CD74, CD33, CD32, and L-Ferritin. The increase in these seven Iba $1^{\text {low }} \mathrm{MOI}^{\text {high }}$ populations was typically accompanied by a reduction in the respective Iba $1^{\text {high }} \mathrm{MOI}^{\text {low }}$ populations, albeit this reduction did not reach significance for all seven of these MOIs (Fig. 3A-E, G, K). This suggests a model for the emergence of an Iba $1^{\text {low }}$ population or populations in $\mathrm{AD}$, at the expense of an Iba $1^{\text {high }}$ population or populations. No significant changes in the Iba1-CD206, Iba1-CD163 and Iba1-P2RY12 populations were identified in AD (Fig. 3H, I). In addition, a significant increase in the Iba $1^{\text {high }}$ TMEM119 ${ }^{\text {low }}$ population was observed in $\mathrm{AD}$, although this change was not accompanied by significant changes in the Iba $1^{\text {high }}$ TMEM119 $19^{\text {high }}$ or Iba $1^{\text {low }}$ TMEM119 ${ }^{\text {high }}$ populations (Fig. 3K).

\section{Iba $1^{\text {low }}$ myeloid cells highly express activation markers}

Next, we sought to further characterise the Iba $1^{\text {low }}$ $\mathrm{MOI}^{\text {high }}$ population, the most changed population in $\mathrm{AD}$, to understand how they differed from their respective Iba $1^{\text {high }} \mathrm{MOI}^{\text {high }}$ population (Fig. 4). We calculated the mean population intensity for each MOI by determining where the centre of each Iba1-MOI population was on the contour plots presented in Fig. 2. We used the mean population intensities for each marker to determine differences in marker expression between the Iba $1^{\text {low }}$ MOI $^{\text {high }}$ and Iba $1^{\text {high }} \mathrm{MOI}^{\text {high }}$ populations in normal and AD MTG. It is important to note that the mean single-cell L-Ferritin average intensity was not compared between the Iba1-L-Ferritin populations as we did not identify an Iba $1^{\text {high }}$ L-Ferritin ${ }^{\text {high }}$ population.

Of the seven MOIs with an increase in the Iba $1^{\text {low }}$ population in $\mathrm{AD}$, the mean population intensity of $\mathrm{CD} 45$, HLA-DR, CD14, CD74, and CD32 was significantly higher in the Ibal ${ }^{\text {low }} \mathrm{MOI}^{\text {high }}$ population relative to the Iba ${ }^{\text {high }}$ MOI $^{\text {high }}$ population in both normal and $A D$, suggesting that cells with the highest MOI expression were those with low Iba1 (Fig. 4A-D, G). These MOIs are generally associated with microglial activation functions. While we identified no increase in the Iba $1^{\text {low }} \mathrm{CD} 206^{\text {high }}$ population in $\mathrm{AD}$, the mean population intensity of CD206 was higher in the Iba1 ${ }^{\text {low }} \mathrm{CD} 206^{\text {high }}$ population relative to the Iba $1^{\text {high }} \mathrm{CD} 206^{\text {high }}$ population in both normal and AD (Fig. 4F).

There was no increase in the abundance of the Iba $1^{\text {low }}$ P2RY12 $2^{\text {high }}$ and Iba1 ${ }^{\text {low }}$ TMEM119 ${ }^{\text {high }}$ populations in $\mathrm{AD}$, distinguishing P2RY12 and TMEM119 from the

(See figure on next page.)

Fig. 2 Novel single cell analysis identifies change in Iba1-MOI cell populations in AD. Iba1 was immunofluorescently co-labelled with markers in the normal and AD human middle temporal gyrus. The single cell Iba1-MOI analysis was used to quantify changes in the proportions of three Iba1-MOI populations in AD: 1. Iba $1^{\text {low }} \mathrm{MOl}^{\text {high }}$, 2. Iba $1^{\text {high }} \mathrm{MOl}^{\text {high }}$, and 3. Iba $1^{\text {high }} \mathrm{MOI}^{\text {low }}(\mathbf{a})$. The MOls immunohistochemically stained for and quantified included CD45 (b, c), HLA-DR (d, e), CD14 (f, g), CD74 (h, i), CD33 (j, k), CD206 (I), CD32 (m, n), CD163 (o, p), P2RY12 (q, r), TMEM119 (s, $\mathbf{t}$ ), and L-Ferritin $(\mathbf{u}, \mathbf{v})$. Example contour plots of Iba1 against MOI average intensity with the gates of the Iba1-MOI populations are presented for one normal and one AD case for CD45 (b), HLA-DR (d), CD14 (f), CD74 (h), CD33 (j), CD206 (l), CD32 (n), CD163 (p), P2RY12 (q), TMEM119 (s), and L-Ferritin $(\mathbf{u})$. The net change in the distribution of the Iba1-MOl average intensities in AD is presented as a heat map of the normalised change (c, e, $\mathbf{g}, \mathbf{i}, \mathbf{k}, \mathbf{m}, \mathbf{o}, \mathbf{r}, \mathbf{t}, \mathbf{v})$. The $x$ - and $y$-axis labels and heatmap scale are presented in ( $\mathbf{w})$ 


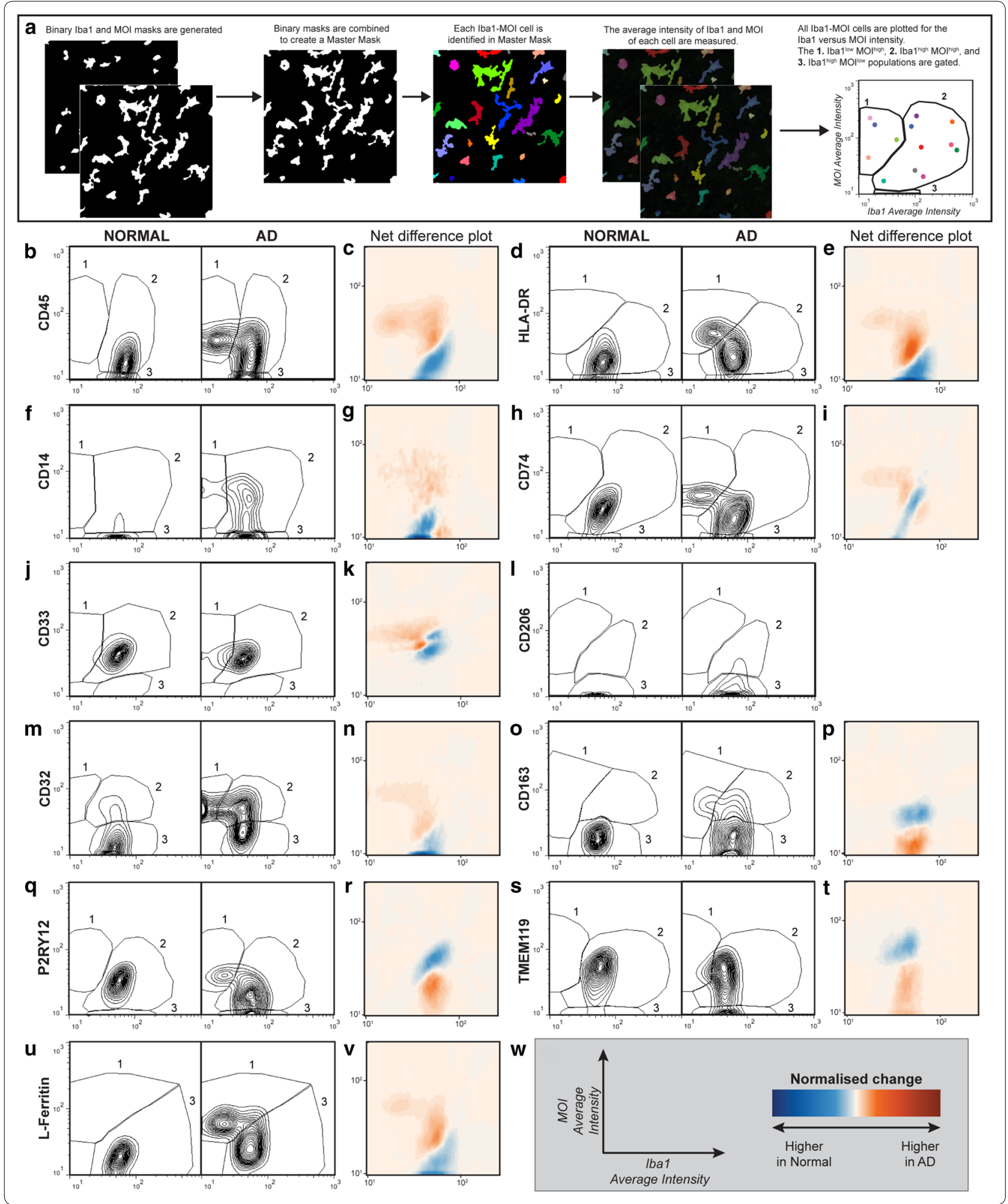

other MOIs. However, unexpectedly, in both normal and $\mathrm{AD}$ cases the mean population intensity of P2RY12 was increased in the Iba ${ }^{\text {low }} \mathrm{P} 2 \mathrm{RY} 12^{\text {high }}$ population relative to the Iba ${ }^{\text {high }} \mathrm{P} 2 \mathrm{RY} 12^{\text {high }}$ population in both normal and AD cases (Fig. 4I). In this way, P2RY12 aligns with the MOIs generally associated with microglial activation 
Fig. $\left.3 \mathrm{lba} 1^{\text {low }} \mathrm{MO}\right|^{\text {high }}$ populations are increased in AD. Iba1-MOI populations were identified by immunofluorescent co-labelling of Iba1 with markers CD45 (a), HLA-DR (b), CD14 (c), CD74 (d), CD33 (e), CD206 (f), CD32 (g), CD163 (h), P2RY12 (I), TMEM119 (j), and L-Ferritin (k). Following the single cell Iba1-MOI analysis, the abundance of the $\mid \mathrm{ba} 1^{\text {low }} \mathrm{MOI}^{\text {high }}, \mathrm{Iba} 1^{\text {high }} \mathrm{MOI}^{\text {high }}$, and $\mathrm{Iba} 1^{\text {high }} \mathrm{MOI}^{\text {low }}$ populations were quantified as a percentage of the total Ibal-MOI population identified in each normal and AD case. The abundance of each Iba1-MOI population was compared between control and AD using a Mann-Whitney test. Data are presented as mean abundance \pm SD $(\mathrm{n}=7$ or 8). Significance of differences between normal and AD: ${ }^{* * *} p \leq 0.001,{ }^{* *} p \leq 0.01,{ }^{*} p \leq 0.05$

functions. In contrast, there was no change in the mean single-cell TMEM119 average intensity between the Iba ${ }^{\text {low }}$ TMEM119 ${ }^{\text {high }}$ and Iba $1^{\text {high }}$ TMEM119 ${ }^{\text {high }}$ populations in normal and AD cases (Fig. 4J).

The changes in the proportions of Iba1-MOI populations demonstrate an increase in the expression of MOIs and a reduction in Iba1. The mean MOI average intensities per cell also demonstrate that the reduced Iba1 expression observed in AD is accompanied by an increase in the expression of a subset of MOIs. The subset of MOIs that is increased in this Iba $1^{\text {low }}$ population were CD45, HLA-DR, CD14, CD74, CD206 and CD32, which have previously been associated with microglial activation (Additional file 1: Table S1).

\section{The abundance of the lba ${ }^{\text {low }}$ myeloid cell populations correlated with tau load but not amyloid beta}

Next we correlated the abundance of the Ibal ${ }^{\text {low }} \mathrm{MOI}^{\text {high }}$ populations with amyloid beta and tau load in $\mathrm{AD}$ cases (Table 2). Aside from CD74 and CD33, all the MOIs that showed an increase in the abundance of the Iba $1^{\text {low }} \mathrm{MOI}^{\text {high }}$ population in AD cases showed significant strong linear correlations with tau pathology load (Table 2). CD206, exclusively expressed by perivascular macrophages in the human brain, did not show an increase in the $\mathrm{Iba} 1^{\text {low }} \mathrm{CD} 206^{\text {high }}$ population in $\mathrm{AD}$. Despite this, the abundance of the Ibal ${ }^{\text {low }}$ CD206 ${ }^{\text {high }}$ population significantly correlated strongly with tau pathology load (Table 2).

For all MOIs, the abundance of the Iba $1^{\text {low }} \mathrm{MOI}^{\text {high }}$ population did not correlate with amyloid beta load in AD (Table 2). We hypothesised that rather than correlating with overall amyloid beta load, the Iba $1^{\text {low }}$ population might be spatially distributed around amyloid beta plaques. To test this hypothesis, we developed a spatial analysis pipeline to quantify the abundance of Iba $1^{\text {low }}$ cells at different distances from amyloid beta plaques in
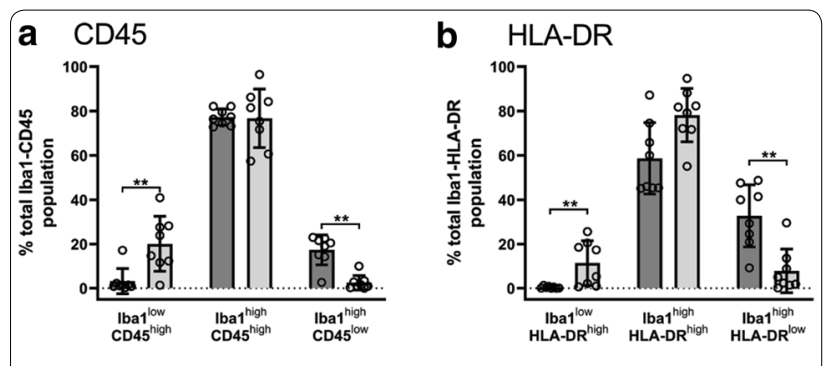

c $\mathrm{CD} 14$
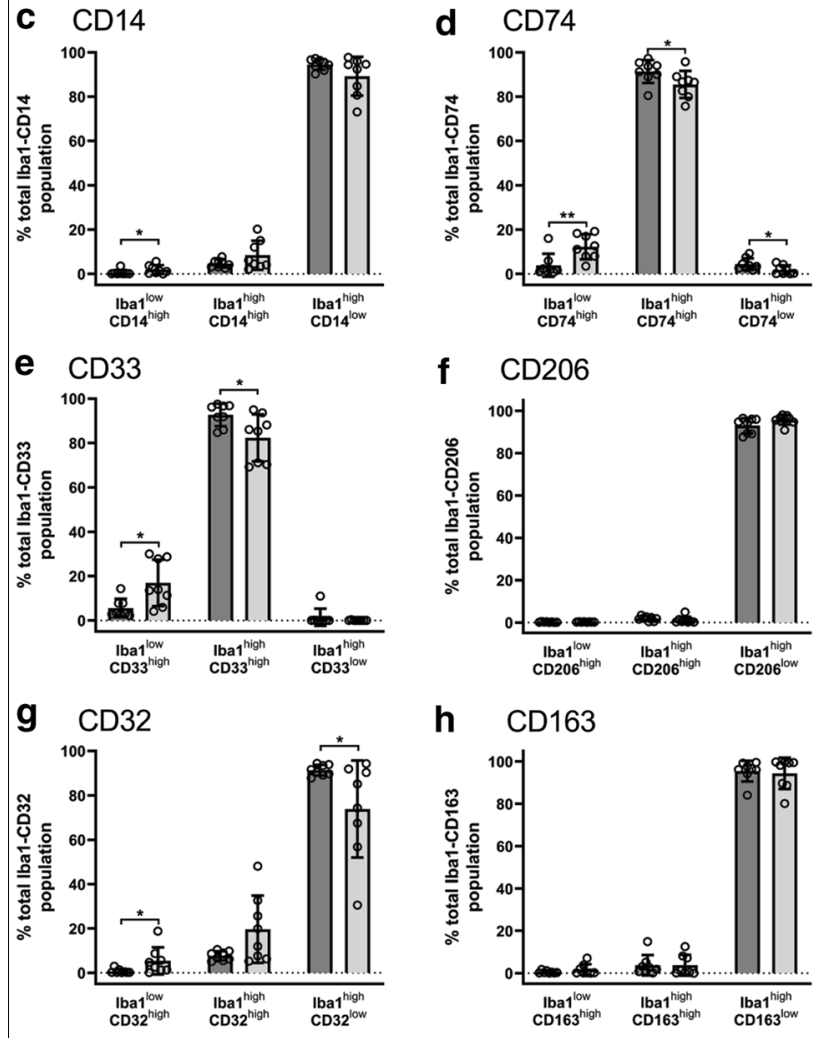

h $\quad$ CD163

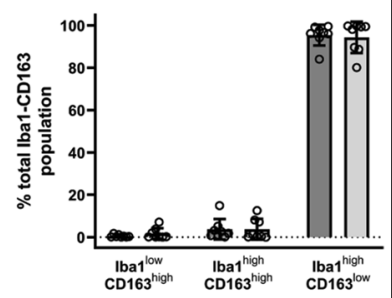

i P2RY12
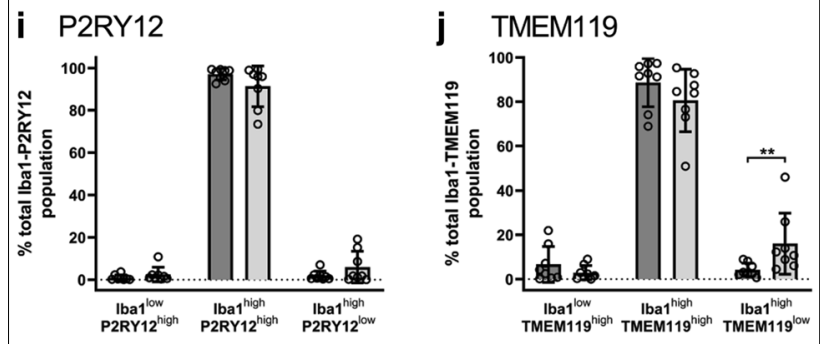

k L-Ferritin

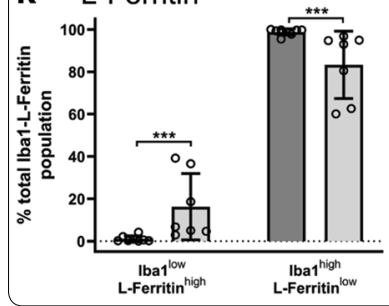

Normal

$A D$ 
Fig. $4 \mathrm{lba} 1^{\text {low }} \mathrm{MOI}^{\text {high }}$ population shows higher expression of activation markers than the respective $\mid \mathrm{ba} 1^{\text {high }} \mathrm{MOI}^{\text {high }}$ populations. Iba1-MOI populations were identified by immunofluorescent co-labelling of Iba1 with markers CD45 (a), HLA-DR (b), CD14 (c), CD74 (d), CD33 (e), CD206 (f), CD32 (g), CD163 (h), P2RY12 (I), and TMEM119 (J). The mean population intensity of the markers was measured for the $\mathrm{Iba} \mathrm{1}^{\text {low }} \mathrm{MOI}^{\text {high }}$ and $\mathrm{Iba} \mathrm{I}^{\text {high }} \mathrm{MOl}^{\text {high }}$ populations in each normal and AD case. The mean population intensities of each $\mathrm{MOI}$ were compared between the Iba1-MOI populations, and normal and AD using a two-way ANOVA with Tukey's multiple comparisons test. Data are presented as mean $\pm S D(n=7-8)$. Significance of differences between Iba1-MOI populations, and normal and AD: ${ }^{* * * *} p \leq 0.0001,{ }^{* * *} p \leq 0.001,{ }^{* *} p \leq 0.01,{ }^{*} p \leq 0.05$

AD MTG (Fig. 5A). To identify Iba ${ }^{\text {low }}$ cells, Iba1 was co-labelled with two MOIs: L-Ferritin and HLA-DR. We chose these MOIs because high L-Ferritin expression best delineated the Iba $1^{\text {low }}$ population, and HLA-DR is a MOI previously shown to be highly expressed by microglia around amyloid beta plaques [17, 49, 56]. Iba1-LFerritin-HLA-DR cells were identified as being plaque (on plaques), plaque-adjacent (5-50 $\mu \mathrm{m}$ from plaques), or non-plaque ( $>50 \mu \mathrm{m}$ from plaques).

We first quantified the proportion of total myeloid cells at each spatial location relative to amyloid beta plaques (Fig. 5B). Only $18.1 \pm 3.22 \%$ of total Iba1-L-FerritinHLA-DR cells were located on plaques (Fig. 5C). We subsequently analysed the relative proportions of Iba $1^{\text {low }}$ and Iba $1^{\text {high }}$ cells at each spatial location relative to plaques (Fig. 5D, E), With no difference observed at different spatial locations (Fig. 5D, E). Therefore, the abundance of the Iba $1^{\text {low }}$ population did not correlate with amyloid beta load and Ibal ${ }^{\text {low }}$ cells were not spatially distributed around amyloid beta plaques.

\section{Iba $1^{\text {low }}$ microglia, but not perivascular macrophages,} co-express L-Ferritin and activation MOls

While the Iba $1^{\text {low }}$ population in $\mathrm{AD}$ was best delineated by high expression of L-Ferritin, a protein specifically expressed by dystrophic microglia, an Iba $1^{\text {low }}$ CD206 $6^{\text {high }}$ perivascular macrophage population was also identified $[45,57]$. Thus, the Iba $1^{\text {low }}$ population consists of both microglia and perivascular macrophages and is not fully identified by co-labelling of a single MOI with Iba1. We sought to determine the overlap of different Iba $1^{\text {low }} \mathrm{MOI}^{\text {high }}$ populations and their myeloid cell identity by triple-labelling Iba1, L-Ferritin, and one of a subset of MOIs: HLA-DR (Fig. 6A-D), CD74 (Fig. 6E-H), CD32 (Fig. 6I-L), CD206 (Fig. 6M-P), and TMEM119 (Fig. 6Q-T). This subset of MOIs was chosen because they span different functional states and have different expression patterns
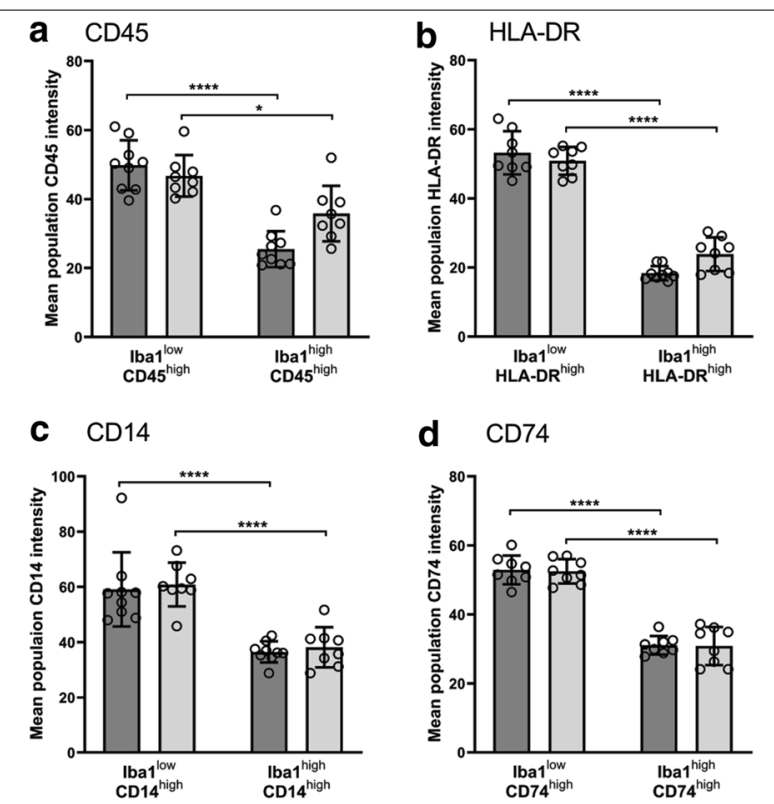

d $\quad \mathrm{CD} 74$

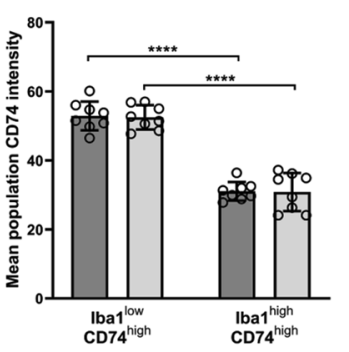

e $\quad \operatorname{CD} 33$

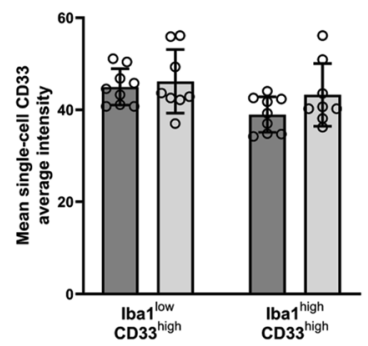

f $\quad$ CD206

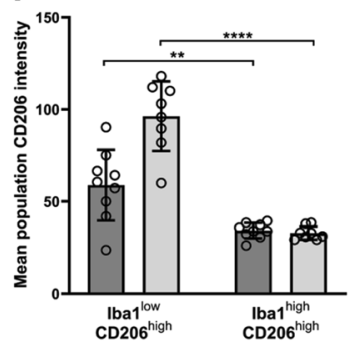

$9 \quad \mathrm{CD} 32$

h $\quad$ CD163
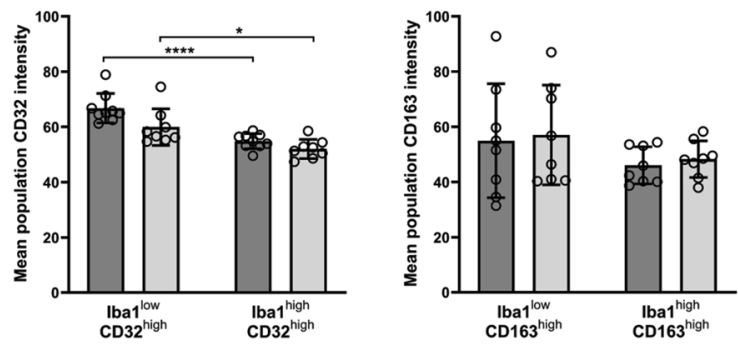

i $\quad$ P2RY12

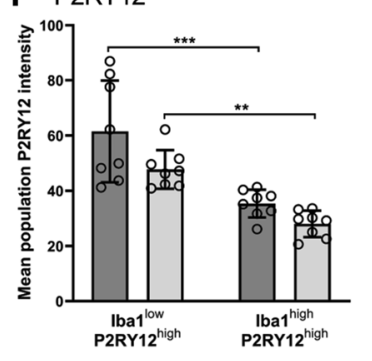

j TMEM119

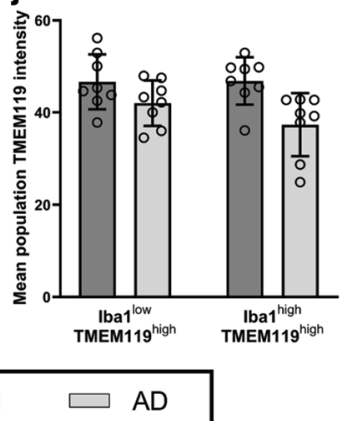


Table 2 Correlations for the abundance of the $\mid \mathrm{ba} 1^{\text {low }}$ $\mathrm{MO}^{\text {high }}$ populations and amyloid beta and tau load in AD cases

\begin{tabular}{lcclll}
\hline Marker & \multicolumn{2}{l}{ Amyloid beta } & & \multicolumn{2}{l}{ Tau } \\
\cline { 2 - 3 } & R value & $\boldsymbol{p}$ value & & R value & $\boldsymbol{p}$ value \\
\hline CD45 & -0.143 & 0.752 & & 0.810 & 0.022 \\
HLA-DR & 0.0952 & 0.840 & & 0.905 & 0.005 \\
CD14 & -0.262 & 0.536 & & 0.833 & 0.015 \\
CD74 & -0.548 & 0.171 & & 0.571 & 0.151 \\
CD33 & -0.452 & 0.268 & & 0.524 & 0.200 \\
CD206 & 0.167 & 0.703 & & 0.833 & 0.015 \\
CD32 & 0.0476 & 0.935 & & 0.952 & 0.001 \\
CD163 & 0.238 & 0.582 & & 0.619 & 0.115 \\
P2RY12 & -0.214 & 0.619 & & 0.667 & 0.096 \\
TMEM119 & -0.0952 & 0.840 & & 0.714 & 0.429 \\
L-Ferritin & 0.214 & 0.662 & & 0.896 & 0.003 \\
\hline
\end{tabular}

Italicised values were considered statistically significant $(p \leq 0.05)$

across microglia and perivascular macrophages (Additional file 1: Table S1). We used the Iba1-MOI singlecell image analysis pipeline (generating a master mask by combining the binary masks of Iba1, L-Ferritin and the MOI), gated out only the Iba $1^{\text {low }}$ cells from the pooled Iba1-L-Ferritin-MOI population, and then gated the L-Ferritin-MOI populations within the Iba $1^{\text {low }}$ cells. This triple-labelling and gating was carried out in both normal and AD to ensure accurate identification of the L-Ferritin ${ }^{\text {high }}$ MOI $^{\text {low }}$, L-Ferritinhigh $\mathrm{MOI}^{\text {high }}$, and L-Ferritin ${ }^{\text {low }} \mathrm{MOI}^{\text {high }}$ populations, but the proportions of the three Iba $1^{\text {low }}$ L-Ferritin-MOI populations were only quantified in AD cases.

Within the Iba1 ${ }^{\text {low }}$ population, HLA-DR and CD74 showed high co-expression with L-Ferritin (Fig. 6AH). Quantification of L-Ferritin and HLA-DR coexpression in the $\mathrm{Iba} 1^{\text {low }}$ population demonstrated that $69.55 \pm 29.47 \%$ of Iba $1^{\text {low }}$ cells highly expressed both HLA-DR and L-Ferritin (Fig. 6D). The remaining single highly expressing population were primarily L-Ferritin high, constituting $22.26 \pm 32.96 \%$ of total Iba $1^{\text {low }}$ cells (Fig. 6D). Quantification of L-Ferritin and CD74 co-expression demonstrated that $84.97 \pm 9.705 \%$ of Iba1 ${ }^{\text {low }}$ cells highly expressed both CD74 and L-Ferritin (Fig. 6H). No co-expression of CD206 and L-Ferritin was observed on the Iba1 ${ }^{\text {low }}$ population (L-Ferritin ${ }^{\text {high }} \mathrm{CD}^{206} 6^{\text {low }}=82.89 \pm 12.54 \%$ and L-Ferritin $^{\text {low }}$ CD206 $6^{\text {high }}=15.59 \pm 12.24 \%$, Fig. 6I-L). This was expected with CD206 being a perivascular macrophage-specific marker in the human brain and no L-Ferritin expression on perivascular macrophages having been previously identified [57].
Iba1 ${ }^{\text {low }}$ cells were somewhat evenly distributed in the L-Ferritin ${ }^{\text {low }}$ CD32 $2^{\text {high }}$, L-Ferritin ${ }^{\text {high }}$ CD $32^{\text {high }}$ and L-Ferritin ${ }^{\text {high }} \mathrm{CD} 32^{\text {low }}$ populations (Fig. 6M-P); a high percentage of Iba $1^{\text {low }}$ cells were identified as either L-Ferritin ${ }^{\text {high }} \mathrm{CD} 32^{\text {low }}$ or L-Ferritin $^{\text {low }} \mathrm{CD} 32^{\text {high }}$ with only a small percentage of Iba $1^{\text {low }}$ cells highly expressing both L-Ferritin and CD32 (L-Ferritin ${ }^{\text {high }}$ CD32 ${ }^{\text {low }}=42.18 \pm 17.52 \%$ and L-Ferritin $^{\text {low }} \mathrm{CD} 32^{\text {high }}=32.01 \pm 13.60 \%$, Fig. $6 \mathrm{P}$; L-Ferritin $^{\text {high }} \mathrm{CD} 32^{\text {high }}=22.53 \pm 12.57 \%$, Fig. $6 \mathrm{P}$ ). This may be attributed to the high CD32 expression by both perivascular macrophages and microglia in the $\mathrm{AD}$ brain [57]. Microglial-specific marker, TMEM119, also showed little to no co-expression with L-Ferritin, with only $21.41 \pm 18.64 \%$ of Iba $1^{\text {low }}$ cells highly expressing TMEM119 and L-Ferritin (Fig. 6Q-T). Therefore, while both TMEM119 and L-Ferritin are both specifically expressed by microglia, they are not expressed by the same Iba $1^{\text {low }}$ microglial population.

\section{Discussion}

In this study, we used novel quantification methods to determine the expression of 11 microglial proteins in post-mortem human AD cortex. Using a novel singlecell image analysis pipeline, we identified Iba $1^{\text {low }} \mathrm{MOI}^{\text {high }}$ microglial populations that were increased in the $\mathrm{AD}$ cortex. Further investigation of the Iba $1^{\text {low }} \mathrm{MOI}^{\text {high }}$ populations revealed that their abundances correlate with tau pathology load. Iba $1^{\text {low }}$ myeloid cells were best delineated by high expression of L-Ferritin, and highly co-expressed L-Ferritin, CD74, and HLA-DR, a phenotype that reflects dysfunction. The results presented in this study are summarised in Additional file 1: Figure S3.

While the Iba $1^{\text {low }}$ population was best delineated by high L-Ferritin expression, Iba ${ }^{\text {low }}$ L-Ferritin ${ }^{\text {high }}$ cells also highly expressed both HLA-DR and CD74. This protein expression signature parallels the transcriptomic signature of the human $\mathrm{AD}$ microglial subpopulation identified using single-cell transcriptomic technologies [17]. The AD pathology-associated microglial population was one of four microglial subpopulations identified in normal and AD human prefrontal cortex using single nuclear RNA sequencing technology. This microglial subpopulation was overrepresented in high pathology load $A D$ cases and was enriched with 77 transcripts relative to the other three microglial subpopulations, including MOIs L-Ferritin, HLA-DR, CD74, and CD14 that we investigated in this study [17]. Therefore, our results provide immunohistochemical validation of this $\mathrm{AD}$ pathologyassociated population, although our spatial analysis shows these microglia are not specifically clustered near plaques. 


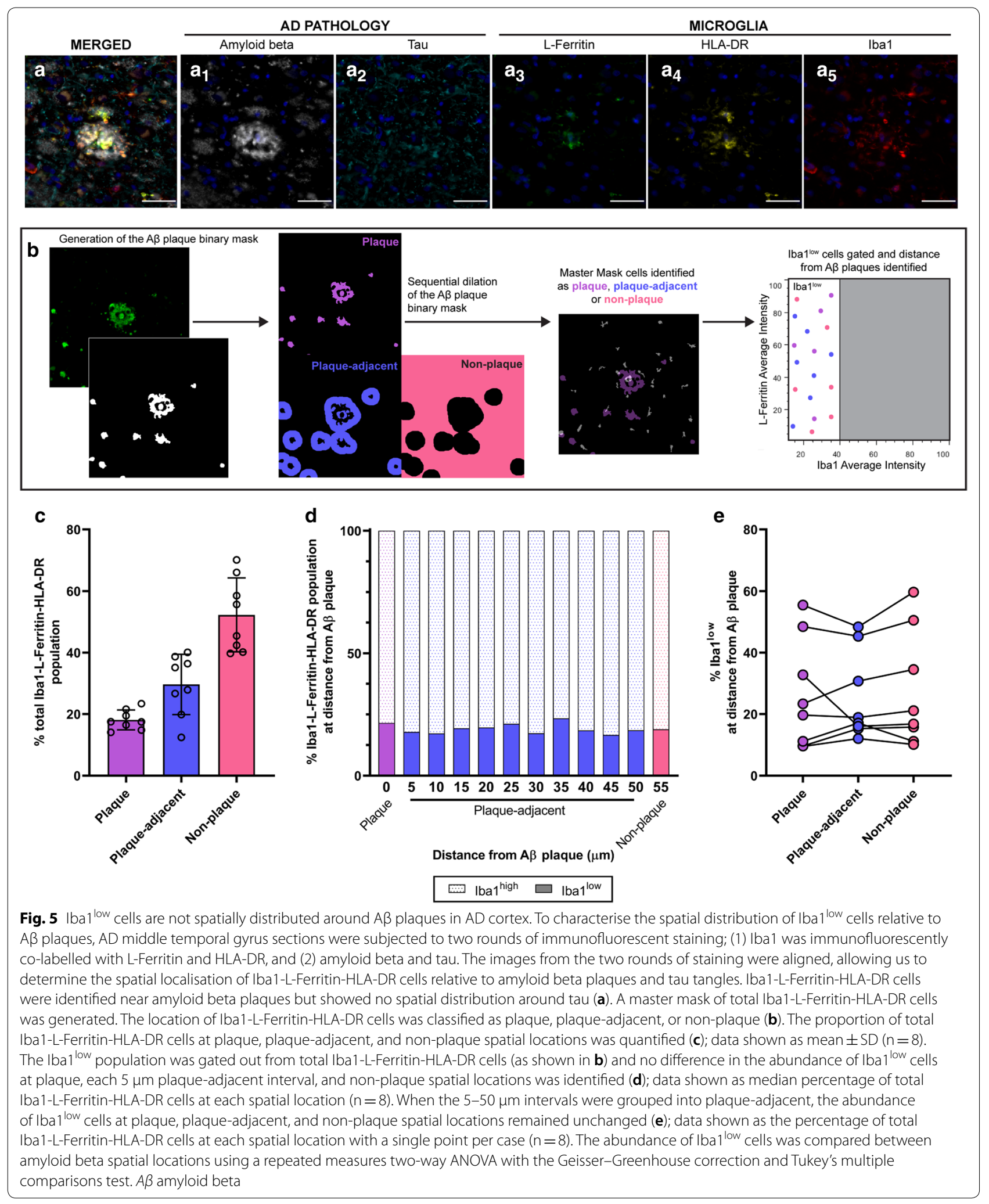


In the human brain, L-Ferritin is a specific marker of dystrophic, dysfunctional microglia [10, 45, 57]. The L-Ferritin ${ }^{\text {high }}$ population identified both here and by Mathys et al. [17] is therefore likely to be dysfunctional. This high expression of L-Ferritin implicates iron dysregulation as a key driver of microglial dysfunction in $\mathrm{AD}$ $[11,59-61]$. Interestingly, the reduced Iba1 expression in this population also suggests dysfunction. Iba1 is key to microglial membrane ruffling and phagocytosis, and a reduction in expression could suggest perturbed phagocytic capabilities [47]. Therefore, the Iba ${ }^{\text {low }}$ L-Ferritin ${ }^{\text {high }}$ phenotype is a unique immunohistochemical signature to identify dysfunctional microglia in the human AD brain.

We identified strong correlations between the abundance of the Iba $1^{\text {low }}$ L-Ferritin ${ }^{\text {high }}$ and Iba $1^{\text {low }}$ HLA$\mathrm{DR}^{\text {high }}$ (and other Iba1 ${ }^{\text {low }} \mathrm{MOI}^{\text {high }}$ ) populations with tau load, but not with amyloid beta load. The correlations of the Iba $1^{\text {low }}$ populations with tau load is likely indicative of an interaction between microglial function and aggregate pathology, where microglial dysfunction and loss of microglial trophic support is predicted to drive the formation of tau pathology $[10,45]$. This relationship has been demonstrated in post-mortem human AD tissue utilising the predictability of tau spread according to Braak staging to investigate the temporal relationship between microglial dysfunction and regional pathology [10]. L-Ferritin-positive dystrophic microglia were identified in Braak Stage I middle temporal gyrus devoid of tau pathology and were more abundant in entorhinal cortex with significant neurodegeneration and tau pathology [10]. Microglial dysfunction and the related loss of trophic support, as demonstrated by high L-Ferritin immunoreactivity and dystrophic morphology, are believed to precede the neurodegeneration and tau pathology in AD. Furthermore, the extent of microglial dystrophy further increases as neurodegeneration advances [12]. Together, with previous temporal relations between microglial dystrophy and tau previously realised, the correlations identified here between the Iba $1^{\text {low }}$ populations and tau pathology further support the conclusion that the Iba $1^{\text {low }}$ population is a dysfunctional microglial population in $\mathrm{AD}$.
Given that microglia are known to interact and phagocytose amyloid beta in $\mathrm{AD}$, we expected a correlation between the $\mathrm{AD}$-associated Ibal ${ }^{\text {low }}$ population and amyloid load [62-68]. We investigated the spatial relationship between the dysfunctional Iba $1^{\text {low }}$ population and amyloid beta plaques $[16,17]$. However, the Ibal ${ }^{\text {low }}$ population identified by high L-Ferritin and/or high HLA-DR expression was not especially spatially distributed close to amyloid beta plaques. This is in direct contrast to disease-associated microglia in AD mice, including those expressing high L-Ferritin, identified around AD plaques $[16,69]$. Human disease-associated microglia may indeed interact with amyloid beta at a certain time point or time points in disease, but these interactions may not persist in end-stage AD human tissue. Alternatively, this difference may reflect species differences. While AD pathology-associated microglia populations highly express phagocytosis-associated genes, high L-Ferritin expression suggests that iron dysregulation in conjunction with amyloid beta phagocytosis drive AD pathology-associated microglial signatures [11, 59-61]. In the human AD brain, iron is heavily concentrated at the centre of amyloid beta plaques and has been implicated in the aggregation of amyloid beta fibrils, demonstrating the likelihood of amyloid beta-iron interactions in AD [70, 71]. Therefore, the interplay between multiple pathogenic processes in $\mathrm{AD}$ likely drive the dysfunctional signature identified here and the associated changes in microglial function.

The characteristics of the Iba $1^{\text {low }}$ population could be interpreted as evidence for the pro-inflammatory hypothesis as well as the dysfunctional hypothesis. While it could be concluded that the Ibal ${ }^{\text {low }}$ populations we identified provide support for the dysfunctional hypothesis of $\mathrm{AD}$, these Iba $1^{\text {low }}$ populations could also be considered chronically active and neurotoxic. Indeed, the Iba $1^{\text {low }}$ populations were best delineated by high L-Ferritin expression, but the Ibal ${ }^{\text {low }}$ populations also expressed high levels of other MOIs associated with activation functions. The Iba $1^{\text {low }}$ populations showed higher mean MOI average intensities per cell of CD45, HLADR, CD14, CD74, and CD32 relative to their respective Iba $1^{\text {high }}$ population. Therefore, the increased presence of the Iba ${ }^{\text {low }}$ population in the human AD brain could

\footnotetext{
(See figure on next page.)

Fig. $6 \mathrm{Iba} 1^{\text {low }}$ population co-expresses of L-Ferritin, HLA-DR, and CD74. To determine the co-expression of dysfunctional marker, L-Ferritin, with other immunophenotype MOIs on the Iba1 ${ }^{\text {low }}$ population, Iba1 was immunofluorescently co-labelled with L-Ferritin and one other MOI; HLA-DR $(\mathbf{a}-\mathbf{d})$, CD74 (e-h), CD206 (i-l), CD32 (m-p), and TMEM119 (q-t). All Iba1-L-Ferritin-MOl cells were pooled from all normal and AD cases and plotted for their Ibal average intensity against L-Ferritin average intensity to identify the Iba ${ }^{\text {low }}$ population $(\mathbf{a}, \mathbf{e}, \mathbf{i}, \mathbf{m}, \mathbf{q})$. All Iba $1^{\text {low }}$ cells from all normal and $\mathrm{AD}$ cases were subsequently plotted for their $\mathrm{MOI}$ average intensity against L-Ferritin average intensity to identify three L-Ferritin-MOI populations; 1. L-Ferritin high $\mathrm{MOI}^{\text {low }}$, 2. L-Ferritin high $\mathrm{MOI}^{\text {high }}$, and 3. L-Ferritin ${ }^{\text {low }} \mathrm{MOl}^{\text {high }}(\mathbf{b}, \mathbf{f}, \mathbf{j}, \mathbf{n}, \mathbf{r})$. An example of the L-Ferritin-MOI gating is shown on a single AD case for each MOI (c, $\mathbf{g}, \mathbf{k}, \mathbf{o}, \mathbf{s})$. The abundance of each L-Ferritin-MOI population was quantified as a percentage of total Iba $1^{\text {low }}$ cells identified with each triple label $(\mathbf{d}, \mathbf{h}, \mathbf{l}, \mathbf{p}, \mathbf{t})$; data presented as mean $(n=8)$
} 


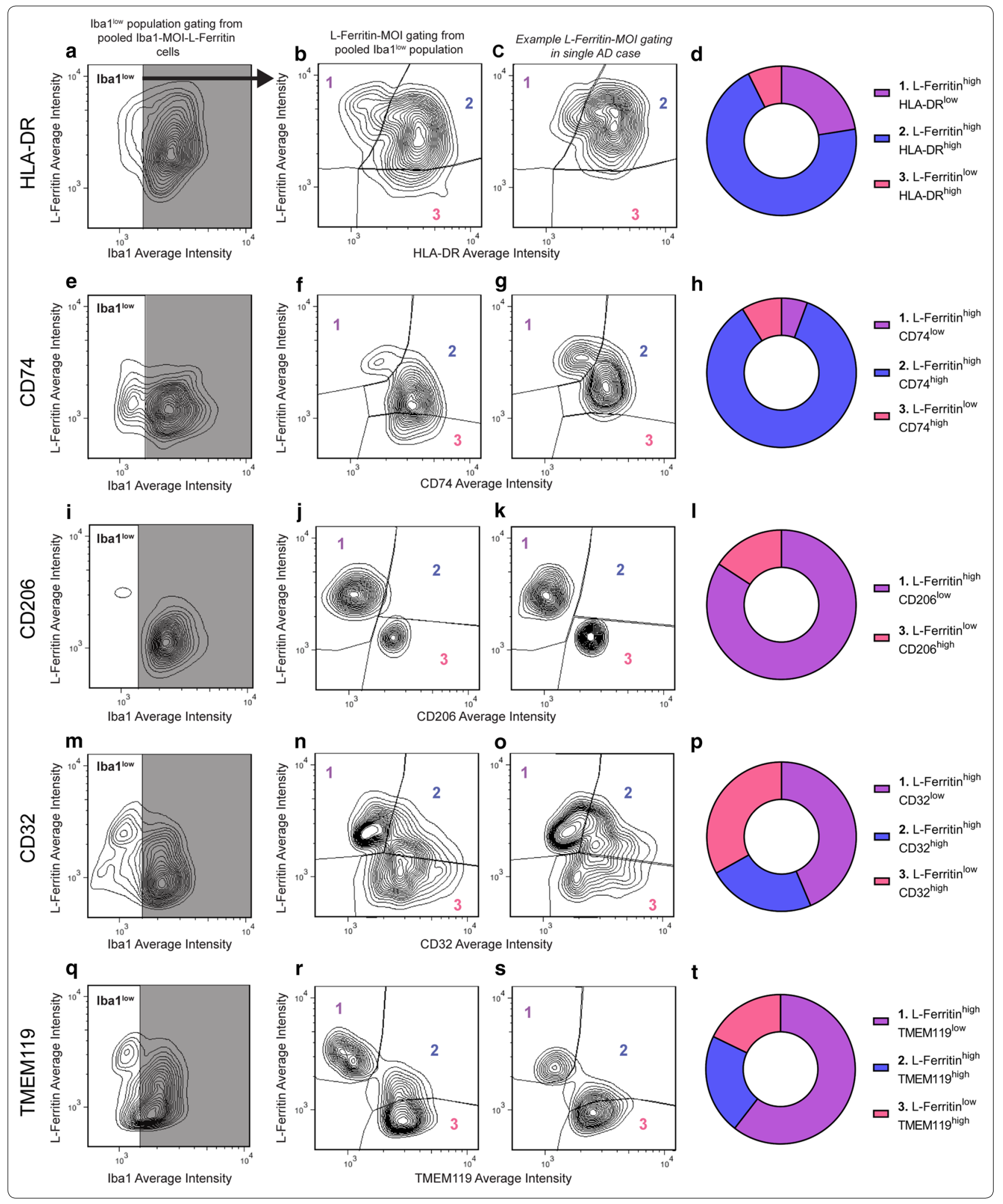


support the contrasting pro-inflammatory hypothesis. However, changes in microglial morphology and phenotype typically associated with chronic activation can also occur as part of cell senescence [13]. Aged microglia express inflammatory proteins not expressed by homeostatic microglia and accumulate lipid molecules. This is a signature that is enhanced in $\mathrm{AD}$ pathology-associated microglia $[16,17,19,72]$. Because the MOIs up-regulated by the Iba1 ${ }^{\text {low }}$ population span numerous and somewhat polarising functions, these populations are showing signs of exaggerated microglial ageing with impaired or dysfunctional intercellular communications [13]. The exacerbated activation state of the Iba $1^{\text {low }}$ population we identified does not necessarily reflect a functional activation state, but instead a dysfunctional one. The characterisation of this dysfunctional microglial population demonstrates the complexity of microglial changes in AD.

By identifying Iba $1^{\text {low }}$ populations that expressed L-Ferritin, specific for microglia, or CD206, specific for perivascular macrophages, we confirmed that both myeloid cell populations contribute to the Iba $1^{\text {low }}$ population in AD. Identifying an Iba $1^{\text {low }} \mathrm{CD} 206^{\text {high }}$ population indicates that PVMs comprise a substantial proportion of the Iba1 ${ }^{\text {low }}$ population. While perivascular macrophages do not express dysfunctional MOI L-Ferritin, the perivascular macrophage Iba $1^{\text {low }}$ population exhibits low Iba1 expression, hypothesised to be a sign of dysfunction. The higher expression, by the Iba $1^{\text {low }} \mathrm{MOI}^{\text {high }}$ than Iba $1^{\text {high }}$ $\mathrm{MOI}^{\text {high }}$ populations, of MOIs associated with activation was also observed with MOIs highly expressed by perivascular macrophages: CD14, CD206, and CD32 [23, 57, 73]. Given that perivascular macrophages phagocytose amyloid beta aggregating around cerebral blood vessels, and the finding of blood-brain barrier breakdown in $\mathrm{AD}$, the maintenance of normal perivascular macrophage function in late AD seems unlikely [74, 75]. Microglia and perivascular macrophages have key phenotypic differences in the normal brain, including their signatures of dysfunction. Overall, our data suggest that both microglia and perivascular macrophages are dysfunctional in AD.

This is one of the first immunohistochemical studies to validate single cell RNA sequencing AD-associated microglial population signatures. The ability to do this is inherently due to the novel single-cell image analysis method we developed to identify the expression of each MOI. Previous immunohistochemical studies have relied on tissue-wide measures, like the tissue-wide integrated intensity measures presented in this study, which as we demonstrated, can dilute subtle AD-associated cell-by-cell changes observed in heterogeneous populations like microglia [48]. The heterogeneity of microglia in the human brain has been identified with single-cell RNA sequencing, including the complexity of microglial changes in the human AD brain, albeit without extensive spatial context [16-19]. Single-cell measurements in immunohistochemically stained post-mortem human tissue have allowed for the identification of microglial heterogeneity and phenotypic changes in AD with some anatomical context $[49,57]$. To provide anatomical context to the disease-associated microglial populations identified, integration of immunohistochemical and single-cell RNA sequencing datasets must be achieved. Although no spatial relationship between the dysfunctional Iba1 ${ }^{\text {low }}$ microglia and $\mathrm{AD}$ pathology was identified here, it establishes context for how image analysis capabilities can be harnessed to generate and analyse single-cell data in immunohistochemically labelled tissue.

\section{Conclusions}

Our novel single-cell image analysis pipeline allowed for the identification of an Iba $1^{\text {low }}$ microglial population in immunohistochemically labelled human brain. This population was best delineated by high L-Ferritin expression, leading to the hypothesis that this is a dysfunctional microglial population. The phenotype of this population mirrors that of a human AD pathology-associated microglial subpopulation previously identified in a single cell RNA sequencing study. As such, our immunohistochemical data support the microglial dysfunction hypothesis of $\mathrm{AD}$.

\section{Supplementary information}

Supplementary information accompanies this paper at https://doi. org/10.1186/s40478-020-01047-9.

Additional file 1. Supplementary file containing supplementary methods, image analysis validation, and supplementary tables and figures.

\section{Abbreviations}

AD: Alzheimer's disease; MTG: Middle temporal gyrus; MOI: Marker of interest; CD: Cluster of differentiation; Iba1: Ionised calcium binding adaptor protein 1; HLA-DR: Human leukocyte antigen, DR isotype; A 3 : Amyloid beta; ROI: Region of interest; TSA:Tyramide signal amplification.

\section{Acknowledgements}

We would like to acknowledge Marika Eszes at the Centre for Brain Research (the University of Auckland, New Zealand) for her technical role in the Neurological Foundation of New Zealand's Human Brain Bank and the imaging team at the Biomedical Imaging Research Unit (the University of Auckland, New Zealand).

\section{Authors' contributions}

MEVS, ELS, BR, MD and MAC conceptualized the study. RLMF and MAC collected and processed the human tissue. CT carried out pathological assessment of all cases. MEVS carried out the experimental procedures, with assistance from HCM. MEVS and ELS developed the custom image analysis pipelines, and LCDS developed out file conversion scripts and cell gating 
methods. MEVS and LCDS carried out all quantification. Data analysis and interpretation were carried out by MEVS, ELS, and BR. Manuscript was prepared by MEVS, and ELS, LCDS, HCM, MAC, and BR carried out the critical revisions. $B R, M D$, and $M A C$ supervised the study. All authors read and approved the final manuscript.

\section{Funding}

MEVS is supported by the Neurological Foundation of New Zealand (W \& B Miller scholarship), the University of Auckland, and Brain Research New Zealand. ELS is supported by Marsden FastStart and Rutherford Discovery Fellowship funding from the Royal Society of New Zealand. HCM is supported by the Health Education Trust and Brain Research New Zealand. BR is supported by the Auckland Medical Research Foundation and the Health Research Council of New Zealand. This work was also supported by a programme grant from the Health Research Council of New Zealand. The Neurological Foundation of New Zealand supported the Human Brain Bank.

\section{Availability of data and materials}

The datasets used and/or analysed during the current study available from the corresponding author on reasonable request.

\section{Ethics approval and consent to participate}

Ethics approval was obtained through the University of Auckland Human Participants Ethics committee (Protocol Number 011654).

\section{Consent for publication}

Not applicable.

\section{Competing interest}

The authors declare that they have no competing interests.

\section{Author details}

1 Department of Anatomy and Medical Imaging, Faculty of Medical and Health Science, University of Auckland, Private Bag 92019, Auckland, New Zealand.

${ }^{2}$ Centre for Brain Research, Faculty of Medical and Health Science, University of Auckland, Private Bag 92019, Auckland, New Zealand. ${ }^{3}$ School of Biological Sciences, Faculty of Science, University of Auckland, Private Bag 92019, Auckland, New Zealand. ${ }^{4}$ Department of Pharmacology and Clinical Pharmacology, Faculty of Medical and Health Science, University of Auckland, Private Bag 92019, Auckland, New Zealand. ${ }^{5}$ Department of Anatomical Pathology, LabPlus, Auckland City Hospital, Auckland, New Zealand. ${ }^{6}$ Present Address: School of Biological Sciences, Faculty of Science, University of Auckland, Private Bag 92019, Auckland, New Zealand. ${ }^{7}$ Present Address: Department of Pathology and Biomedical Science, Centre for Free Radical Research, University of Otago, 2 Riccarton Avenue, Christchurch 8011, New Zealand.

Received: 27 July 2020 Accepted: 2 October 2020

Published online: 20 October 2020

\section{References}

1. Braak H, Thal DR, Ghebremedhin E, Del Tredici K (2011) Stages of the pathologic process in Alzheimer disease. J Neuropathol Exp Neurol 70:960-969

2. Perry VH (2010) Contribution of systemic inflammation to chronic neurodegeneration. Acta Neuropathol 120:277-286

3. Perry VH, Nicoll JAR, Holmes C (2010) Microglia in neurodegenerative disease. Nat Rev Neurol 6:193-201

4. Guerreiro R, Ph D, Wojtas A, Bras J, Carrasquillo M, Rogaeva E et al (2013) TREM2 variants in AD. N Engl J Med 368:117-127

5. Jonsson T, Stefansson H, Steinberg S, Jonsdottir I, Jonsson P, Snaedal J et al (2013) Variant of TREM2 associated with the risk of AD. N Engl J Med 368:107-116

6. Walker DG, Whetzel AM, Serrano G, Sue LI, Beach TG, Lue LF (2015) Association of CD33 polymorphism rs3865444 with Alzheimer's disease pathology and CD33 expression in human cerebral cortex. Neurobiol Aging 36:571-582

7. Kunkle BW, Grenier-Boley B, Sims R, Bis JC, Damotte V, Naj AC et al (2019) Genetic meta-analysis of diagnosed Alzheimer's disease identifies new risk loci and implicates $A \beta$, tau, immunity and lipid processing. Nat Genet 51:414-430

8. Akiyama H, Barger S, Barnum S, Bradt B, Bauer J, Cole GM et al (2000) Inflammation and Alzheimer's disease. Neurobiol Aging 21:383-421

9. Selkoe DJ, Hardy J (2016) The amyloid hypothesis of Alzheimer's disease at 25 years. EMBO Mol Med 8:595-608

10. Streit WJ, Braak H, Xue QS, Bechmann I (2009) Dystrophic (senescent) rather than activated microglial cells are associated with tau pathology and likely precede neurodegeneration in Alzheimer's disease. Acta Neuropathol 118:475-485

11. Streit WJ, Xue Q-S, Tischer J, Bechmann I (2014) Microglial pathology. Acta Neuropathol Commun 2:142

12. Streit WJ, Khoshbouei H, Bechmann I (2020) Dystrophic microglia in lateonset Alzheimer's disease. Glia 68:845-854

13. Mosher Kl, Wyss-Coray T (2014) Microglial dysfunction in brain aging and Alzheimer's disease. Biochem Pharmacol 88:594-604

14. Streit WJ (2004) Microglia and Alzheimer's disease pathogenesis. J Neurosci Res 77:1-8

15. Ransohoff RM (2016) A polarizing question: do M1 and M2 microglia exist. Nat Neurosci 19:987-991

16. Keren-Shaul H, Spinrad A, Weiner A, Matcovitch-Natan O, Dvir-Szternfeld R, Ulland TK et al (2017) A unique microglia type associated with restricting development of Alzheimer's disease. Cell 169:1276-1290.e17

17. Mathys H, Davila-Velderrain J, Peng Z, Gao F, Mohammadi S, Young JZ et al (2019) Single-cell transcriptomic analysis of Alzheimer's disease. Nature 570:332-337

18. Mathys H, Adaikkan C, Gao F, Young JZ, Manet E, Hemberg M et al (2017) Temporal tracking of microglia activation in neurodegeneration at singlecell resolution. Cell Rep 21:366-380

19. Hammond TR, Dufort C, Dissing-Olesen L, Giera S, Young A, Wysoker A et al (2019) Single-cell RNA sequencing of microglia throughout the mouse lifespan and in the injured brain reveals complex cell-state changes. Immunity 50:253-271.e6

20. Licastro F, Mallory M, Hansen LA, Masliah E (1998) Increased levels of a-1-antichymotrypsin in brains of patients with Alzheimer's disease correlate with activated astrocytes and are affected by APOE 4 genotype. J Neuroimmunol 88:105-110

21. Sanchez-Mejias E, Navarro V, Jimenez S, Sanchez-Mico M, Sanchez-Varo R, Nuñez-Diaz C et al (2016) Soluble phospho-tau from Alzheimer's disease hippocampus drives microglial degeneration. Acta Neuropathol 132:897-916

22. Collawn JF, Benveniste EN (1999) Regulation of MHC class II expression in the central nervous system. Microbes Infect 1:893-902

23. Letiembre M, Liu Y, Walter S, Hao W, Pfander T, Wrede A et al (2009) Screening of innate immune receptors in neurodegenerative diseases: a similar pattern. Neurobiol Aging 30:759-768

24. Liu Y, Walter S, Stagi M, Cherny D, Letiembre M, Schulz-Schaeffer W et al (2005) LPS receptor (CD14): a receptor for phagocytosis of Alzheimer's amyloid peptide. Brain 128:1778-1789

25. Cribbs DH, Berchtold NC, Perreau V, Coleman PD, Rogers J, Tenner AJ et al (2012) Extensive innate immune gene activation accompanies brain aging, increasing vulnerability to cognitive decline and neurodegeneration: a microarray study. J Neuroinflamm 9:1-18

26. Becker-Herman S, Arie G, Medvedovsky H, Kerem A, Shachar I (2005) CD74 is a member of the regulated intramembrane proteolysis-processed protein family. Mol Biol Cell 16:5061-5069

27. Stumptner-Cuvelette $P$, Benaroch $P$ (2002) Multiple roles of the invariant chain in MHC class II function. Biochim Biophys Acta 1542:1-13

28. Bryan KJ, Zhu X, Harris PL, Perry G, Castellani RJ, Smith MA et al (2008) Expression of CD74 is increased in neurofibrillary tangles in Alzheimer's disease. Mol Neurodegener 3:13

29. Satoh J, Kino Y, Motohashi N, Ishida T, Yagishita S, Jinnai K et al (2015) Immunohistochemical characterization of CD33 expression on microglia in Nasu-Hakola disease brains. Neuropathology 35:529-537

30. Griciuc A, Serrano-Pozo A, Parrado ARR, Lesinski ANN, Asselin CNN, Mullin K et al (2013) Alzheimer's disease risk gene cd33 inhibits microglial uptake of amyloid beta. Neuron 78:631-643

31. Malik M, Simpson JF, Parikh I, Wilfred BR, Fardo DW, Nelson PT et al (2013) CD33 Alzheimer's risk-altering polymorphism, CD33 expression, and exon 2 splicing. J Neurosci 33:13320-13325 
32. Castillo E, Leon J, Mazzei G, Abolhassani N, Haruyama N, Saito T et al (2017) Comparative profiling of cortical gene expression in Alzheimer's disease patients and mouse models demonstrates a link between amyloidosis and neuroinflammation. Sci Rep 7:1-16

33. Linehan SA, Martinez-Pomares L, Gordon S (2000) Mannose receptor and scavenger receptor: two macrophage pattern recognition receptors with diverse functions in tissue homeostasis and host defense. Adv Exp Med Biol 479:1-14

34. Colton CA, Mott RT, Sharpe H, Xu Q, Van Nostrand WE, Vitek MP (2006) Expression profiles for macrophage alternative activation genes in $A D$ and in mouse models of AD. J Neuroinflamm 3:1-12

35. Anania JC, Chenoweth AM, Wines BD, MarkHogarth P (2019) The human FcyRII (CD32) family of leukocyte FCR in health and disease. Front Immunol 10:1-17

36. Peress NS, Fleit HB, Perillo E, Kuljis R, Pezzullo C (1993) Identification of Fc gamma RI, II and III on normal human brain ramified microglia and on microglia in senile plaques in Alzheimer's disease. J Neuroimmunol 48:71-79

37. Etzerodt A, Moestrup SK (2013) CD163 and inflammation: biological, diagnostic, and therapeutic aspects. Antioxid Redox Signal 18:2352-2363

38. Dal Bianco A, Bradl M, Frischer J, Kutzelnigg A, Jellinger K, Lassmann H (2008) Multiple sclerosis and Alzheimer's disease. Ann Neurol 63:174-183

39. Pey P, Pearce RK, Kalaitzakis ME, Griffin WST, Gentleman SM (2014) Phenotypic profile of alternative activation marker CD163 is different in Alzheimer's and Parkinson's disease. Acta Neuropathol Commun 2:21

40. Ito D, Imai Y, Ohsawa K, Nakajima K, Fukuuchi Y, Kohsaka S (1998) Microglia-specific localisation of a novel calcium binding protein, Iba1. Mol Brain Res 57:1-9

41. Haynes SE, Hollopeter G, Yang G, Kurpius D, Dailey ME, Gan WB et al (2006) The P2Y12 receptor regulates microglial activation by extracellular nucleotides. Nat Neurosci 9:1512-1519

42. Moore CS, Ase AR, Kinsara A, Rao VTS, Michell-Robinson M, Leong SY et al (2015) P2Y12 expression and function in alternatively activated human microglia. Neurol Neuroimmunol Neuroinflamm 2:e80

43. Bennett ML, Bennett FC, Liddelow SA, Ajami B, Zamanian JL, Fernhoff NB et al (2016) New tools for studying microglia in the mouse and human CNS. Proc Natl Acad Sci USA 113:E1738-E1746

44. Satoh JI, Kino Y, Asahina N, Takitani M, Miyoshi J, Ishida T et al (2016) TMEM119 marks a subset of microglia in the human brain. Neuropathology 36:39-49

45. Lopes KO, Sparks DL, Streit WJ (2008) Microglial dystrophy in the aged and Alzheimer's disease brain is associated with ferritin immunoreactivity. Glia 56:1048-1060

46. Imai Y, Ibata I, Ito D, Ohsawa K, Kohsaka S (1996) A novel gene iba1 in the major histocompatibility complex class III region encoding an EF hand protein expressed in a monocytic lineage. Biochem Biophys Res Commun 224:855-862

47. Ohsawa K, Imai Y, Kanazawa H, Sasaki Y, Kohsaka S (2000) Involvement of Iba1 in membrane ruffling and phagocytosis of macrophages/microglia. J Cell Sci 113:3073-3084

48. Hopperton KEK, Mohammad D, Trépanier MOM, Giuliano V, Bazinet RPR (2017) Markers of microglia in postmortem brain samples from patients with Alzheimer's Disease: a systematic review. Mol Psychiatry 23:177-198

49. Serrano-Pozo A, Gómez-Isla T, Growdon JH, Frosch MP, Hyman BT (2013) A phenotypic change but not proliferation underlies glial responses in Alzheimer disease. Am J Pathol 182:2332-2344

50. Penninger JM, Irie-Sasaki J, Sasaki T, Oliveira-dos-Santos AJ (2001) CD45: new jobs for an old acquaintance. Nat Immunol 2:389-396

51. Masliah E, Mallory M, Hansen L, Alford M, Albright T, Terry R et al (1991) Immunoreactivity of CD45, a protein phosphotyrosine phosphatase, in Alzheimer's disease. Acta Neuropathol 83:12-20

52. Waldvogel HJ, Curtis MA, Baer K, Rees MI, Faull RLM (2007) Immunohistochemical staining of post-mortem adult human brain sections. Nat Protoc 1:2719-2732

53. Murray HC, Low VF, Swanson MEVV, Dieriks BV, Turner C, Faull RLMM et a (2016) Distribution of PSA-NCAM in normal, Alzheimer's and Parkinson's disease human brain. Neuroscience. 330:359-75

54. Murray HC, Swanson MEV, Dieriks BV, Turner C, Faull RLM, Curtis MA (2018) Neurochemical characterization of PSA-NCAM+ cells in the human brain and phenotypic quantification in Alzheimer's disease entorhinal cortex. Neuroscience. 372:289-303
55. Murray HC, Dieriks BV, Swanson MEV, Anekal PV, Turner C, Faull RLM et al (2020) The unfolded protein response is activated in the olfactory system in Alzheimer's disease. Acta Neuropathol Commun 8:109

56. Mattiace LA, Davies P, Dickson DW (1990) Detection of HLA-DR on microglia in the human brain is a function of both clinical and technical factors. Am J Pathol 136:1101-1114

57. Swanson MEV, Murray HC, Ryan B, Faull RLM, Dragunow M, Curtis MA (2020) Quantitative immunohistochemical analysis of myeloid cell marker expression in human cortex captures microglia heterogeneity with anatomical context. Sci Rep 10:11693

58. Dieriks BV, Dean JM, Aronica E, Waldvogel HJ, Faull RLM, Curtis MA (2018) Differential fatty acid-binding protein expression in persistent radial glia in the human and sheep subventricular zone. Dev Neurosci. 40:145-61

59. Jellinger K, Paulus W, Grundke-lqbal I, Riederer P, Youdim MBH (1990) Brain iron and ferritin in Parkinson's and Alzheimer's diseases. J Neural Transm Park Dis Dement Sect 2:327-340

60. Connor JR, Snyder BS, Beard JL, Fine RE, Mufson EJ (1992) Regional distribution of iron and iron-regulatory proteins in the brain in aging and Alzheimer's disease. J Neurosci Res 31:327-335

61. Streit WJ, Xue QS (2009) Life and death of microglia. J Neuroimmune Pharmacol 4:371-379

62. Wisniewski HM, Barcikowska M, Kida E (1991) Phagocytosis of $\beta / A 4$ amyloid fibrils of the neuritic neocortical plaques. Acta Neuropathol 81:588-590

63. Giulian D, Haverkamp L, Li J, Karshin WL, Yu J, Tom D et al (1995) Senile plaques stimulate microglia to release a neurotoxin found in Alzheimer brain. Neurochem Int 27:119-137

64. Cotman CW, Tenner AJ, Cummings BJ (1996) $\beta$-Amyloid converts an acute phase injury response to chronic injury responses. Neurobiol Aging 17:723-731

65. Klegeris A, Walker DG, McGeer PL (1997) Interaction of Alzheimer $\beta$-amyloid peptide with the human monocytic cell line THP-1 results in a protein kinase C-dependent secretion of tumor necrosis factor-a. Brain Res 747:114-121

66. McDonald DR, Brunden KR, Landreth GE (1997) Amyloid fibrils activate tyrosine kinase-dependent signaling and superoxide production in microglia. J Neurosci 17:2284-2294

67. Combs CK, Karlo JC, Kao S-C, Landreth GE (2001) $\beta$-Amyloid stimulation of microglia and monocytes results in TNFa-dependent expression of inducible nitric oxide synthase and neuronal apoptosis. J Neurosci 21:1179-1188

68. Bolmont T, Haiss F, Eicke D, Radde R, Mathis CA, Klunk WE et al (2008) Dynamics of the microglial/amyloid interaction indicate a role in plaque maintenance. J Neurosci 28:4283-4292

69. Meadowcroft MD, Connor JR, Yang QX (2015) Cortical iron regulation and inflammatory response in Alzheimer's disease and APPSWE/PS1 $\triangle E 9$ mice: a histological perspective. Front Neurosci 9:1-16

70. Bush Al (2002) Metal complexing agents as therapies for Alzheimer's disease. Neurobiol Aging 23:1031-1038

71. Collingwood JF, Chong RKK, Kasama T, Cervera-Gontard L, DuninBorkowski RE, Perry G et al (2008) Three-dimensional tomographic imaging and characterization of iron compounds within Alzheimer's plaque core material. J Alzheimer's Dis 14:235-245

72. Marschallinger J, Iram T, Zardeneta M, Lee SE, Lehallier B, Haney MS et al (2020) Lipid-droplet-accumulating microglia represent a dysfunctional and proinflammatory state in the aging brain. Nat Neurosci 23:194-208

73. Durafourt BA, Moore CS, Zammit DA, Johnson TA, Zaguia F, Guiot MC et al (2012) Comparison of polarization properties of human adult microglia and blood-derived macrophages. Glia 60:717-727

74. Thanopoulou K, Fragkouli A, Stylianopoulou F, Georgopoulos S (2010) Scavenger receptor class B type I (SR-BI) regulates perivascular macrophages and modifies amyloid pathology in an Alzheimer mouse model. Proc Natl Acad Sci 107:20816-20821

75. Lapenna A, De Palma M, Lewis CE (2018) Perivascular macrophages in health and disease. Nat Rev Immunol 18:689-702

\section{Publisher's Note}

Springer Nature remains neutral with regard to jurisdictional claims in published maps and institutional affiliations. 